\title{
Lack of an association between $G H R$ exon 3 polymorphism and diabetic nephropathy in the Genetics of Kidneys in Diabetes (GoKinD) population
}

\author{
H. F. Gu • S. Efendic • K. Brismar
}

Received: 9 July 2008 / Accepted: 8 August 2008 / Published online: 5 September 2008

(C) Springer-Verlag 2008

Keywords Diabetic nephropathy · Exon 3 polymorphism . Growth hormone receptor Type 1 diabetes

$\begin{array}{ll}\text { Abbreviations: } \\ \text { DN } & \text { diabetic nephropathy } \\ \text { GH } & \text { growth hormone } \\ \text { GHR } & \text { growth hormone receptor } \\ \text { GoKinD } & \text { Genetics of Kidneys in Diabetes }\end{array}$

To the Editor: Growth hormone (GH) signalling via the GH receptor (GHR) forms the GH/GHR axis and plays an important role in metabolism. There is a genomic deletion of full-length exon 3 ( $d 3$ isoform) in the GHR gene. Previously, the GHRd3 isoform is found to be significantly associated with increased responsiveness to growth hormone [1]. Although the consensus is lacking in subsequent studies [2], GHRd3 has also been found to be associated with hypertension among stroke patients [3]. Recently, a report from our research group has demonstrated that the homozygosity for the GHRd3 allele may have the protective effect on the prevalence of type 2 diabetes [4]. Furthermore, evidence has suggested that the glomerular podocyte is a target for GH action, and the GH/GHR axis may play a role in the development of diabetic nephropathy (DN) $[5,6]$. A recent study has shown that deficiency of GHR in mice ( $G h r$ knockout) causes a reduction in systolic blood pressure and plasma renin levels, as well as an increase in aortic endothelial NO synthase (eNOS) levels

H. F. Gu $(\bowtie) \cdot$ S. Efendic $\cdot$ K. Brismar

Rolf Luft Center for Diabetes Research,

Department of Molecular Medicine and Surgery, L6:B2,

Karolinska Institutet,

Karolinska University Hospital,

17176 Stockholm, Sweden

e-mail: harvest.gu@ki.se
[7]. We thus hypothesise that GHR exon 3 polymorphism may be involved in the pathogenesis of DN.

To test this hypothesis, we have genotyped GHR exon 3 polymorphism in the participants selected from the Genetics of Kidneys in Diabetes (GoKinD) study [8]. This GoKinD cohort consists of 663 (351 male and 312 female) type 1 diabetes patients with DN (cases) and 622 (252 male and 370 female) patients without DN (controls). Among the patients, $\sim 92 \%$ were of European descent, while $\sim 8 \%$ were Americans of Black, Asian, Hispanic or Indian descent. All type 1 diabetes patients were diagnosed according to the World Health Organization criteria [9]. The patients with DN had persistent proteinuria or end-stage renal disease (not due to condition other than diabetes). The patients without DN had persistent normal albuminuria despite them having had type 1 diabetes for at least 15 years and never having been treated with ACE inhibitors. The detailed information of the GoKinD cohort is available at GoKinD database [10] and reference [8]. The study was approved by the local ethics committees and material transfer agreement was completed prior to the study. Genotyping of GHR exon 3 polymorphism was performed with a multiplex PCR protocol [1, 11] and the primers G1, G2 and G3 are recorded in GenBank with the accession number of AF155912. PCR variables were: initial denaturing at $94^{\circ} \mathrm{C}$ for $5 \mathrm{~min} ; 35$ cycles of $94^{\circ} \mathrm{C}$ for $30 \mathrm{~s}, 60^{\circ} \mathrm{C}$ for $30 \mathrm{~s}$ and $72^{\circ} \mathrm{C}$ for $90 \mathrm{~s}$; and a final extension at $72^{\circ} \mathrm{C}$ for $10 \mathrm{~min}$. Genotypes with GHRfI and/or - $d 3$ alleles were detected by $1 \%$ agarose gel electrophoresis. For genotyping quality control in the present study, the patients with and without DN were distributed randomly across PCR plates. Successful genotype calls were $\geq 95 \%$ and plates were randomly genotyped twice for duplication accuracy, which was calculated to be $98 \%$. Furthermore, the sample sizes in both cases (type 1 diabetes with $\mathrm{DN}, n=633$ ) and controls (type 1 diabetes without DN, $n=622$ ), which produced 1,266 case alleles and 1,244 control alleles, were sufficiently 
large to detect at least differences of 0.1 in allele frequency. Allele frequency and genotype distribution for GHR exon 3 polymorphism were tested for Hardy-Weinberg equilibrium. For differences between type 1 diabetes patients with $\mathrm{DN}$ and without $\mathrm{DN}$, the model for comparing allele frequencies in $2 \times 2$ contingency table was tested, while the additive and relevant models for comparing genotype distributions were used. Tests for association between genotypes and quantitative traits were performed using Kruskal-Wallis analysis of ranks for traits with non-normal distributions, or alternatively, ANOVA for normally distributed traits. For association estimation, odd ratios and 95\% confidence intervals were estimated from unconditional logistic regression models. The $p$ value $<0.05$ was considered statistically significant. Analyses were carried out using STATISTICA version 7.0 (Tulsa, OK, USA).

Genotype distributions and allele frequencies of the GHR exon 3 polymorphism in the GoKinD population was in HWD; the results are summarised in Table 1. The frequencies of the GHRd 3 allele in type 1 diabetes patients with DN and without DN were similar $(25.5 \%$ and $25.6 \%$, respectively, $p=0.966$ ). Distribution of three genotypes fIIfI, fI/d3 and $d 3 / d 3$ between type 1 diabetes with $\mathrm{DN}$ and without $\mathrm{DN}$ were not significantly different ( $p=0.469$, additive model). Although allele $d 3$ frequency in female type 1 diabetes patients with DN (25.6\%) was higher than in female type 1 diabetes patients without DN (24.2\%), no significant association was found. Further analyses were done of the differences in phenotypes (quantitative traits) including $\mathrm{HbA}_{1 \mathrm{c}}$, body mass index, creatinine, systatin, cholesterol, high-density lipoprotein, and systolic and diastolic blood pressures among type 1 diabetes patients with or without DN carrying with different genotypes. No statistically significant results were found. The present study thus indicates that GHRd3 allele frequency in the GoKinD type 1 diabetes patients (with and without DN) is similar to the frequency found in Swedish patients with type 2 diabetes (25.3\%) [4]. There was no association between $G H R$ exon 3 polymorphism and DN among type 1 diabetes patients in the GoKinD population.

Table 1 Genotype distribution and allele frequency of the GHR exon 3 polymorphism

\begin{tabular}{lccc}
\hline Variable & $\begin{array}{l}\text { T1D with DN } \\
\text { (male/female) }\end{array}$ & $\begin{array}{l}\text { T1D without DN } \\
\text { (male/female) }\end{array}$ & $\begin{array}{l}p \\
\text { value }\end{array}$ \\
\hline Genotypes & & & \\
$f I / f I$ & $359(182 / 177)$ & $344(142 / 202)$ & 0.469 \\
$f I / d 3$ & $270(151 / 119)$ & $238(91 / 147)$ & \\
$d 3 / d 3$ & $34(18 / 16)$ & $40(19 / 21)$ & \\
Allele $d 3$ & $0.255(0.266 / 0.242)$ & $0.256(0.256 / 0.256)$ & 0.966 \\
frequency & & & \\
\hline
\end{tabular}

T1D, type 1 diabetes
Acknowledgements The authors wish to thank Ms Yvonne Strömberg for excellent laboratory assistance and all individuals participating in the present study. The sample collection of the GoKinD study was supported by the Juvenile Diabetes Research Foundation in collaboration with the Joslin Diabetes Center and George Washington University, and by the United States Centers for Diabetes Control and Prevention. The present study was supported by Novo Nordisk Foundation Consortium, Family Erling-Persson Foundation, Swedish Research Council and Swedish Diabetes Association.

Duality of interest The authors declare that there is no duality of interest associated with this study.

\section{References}

1. Dos Santos C, Essioux L, Teinturier C et al (2004) A common polymorphism of the growth hormone receptor is associated with increased responsiveness to growth hormone. Nat Genet 36:720-724

2. Carrascosa A, Audí L, Fernández-Cancio M et al (2008) The exon 3-deleted/full-length growth hormone receptor polymorphism did not influence growth response to growth hormone therapy over two years in prepubertal short children born at term with adequate weight and length for gestational age. J Clin Endocrinol Metab 93:764-70

3. Horan M, Newsway V, Yasmin Lewis MD et al (2006) Genetic variation at the growth hormone (GH1) and growth hormone receptor (GHR) loci as a risk factor for hypertension and stroke. Hum Genet 119:527-540

4. Strawbridge RJ, Kärvestedt L, Li C et al (2007) GHR exon 3 polymorphism: Association with type 2 diabetes mellitus and metabolic disorder. Growth Horm IGF Res 17:392-398

5. Reddy GR, Pushpanathan MJ, Ransom RF et al (2007) Identification of the glomerular podocyte as a target for growth hormone action. Endocrinology 148:2045-2055

6. Flyvbjerg A (2004) The role of growth hormone in the pathogenesis of diabetic kidney disease. Pediatr Endocrinol Rev 3(Suppl):525-529

7. Egecioglu E, Andersson IJ, Bollano E et al (2007) Growth hormone receptor deficiency in mice results in reduced systolic blood pressure and plasma renin, increased aortic eNOS expression, and altered cardiovascular structure and function. Am J Physiol Endocrinol Metab 292:1418-1425

8. Mueller PW, Rogus JJ, Cleary PA et al (2006) Genetics of Kidneys in Diabetes (GoKinD) study: a genetics collection available for identifying genetic susceptibility factors for diabetic nephropathy in type 1 diabetes. J Am Soc Nephrol 17:1782-1790

9. Alberti KG, Zimmet P (1998) Definition, diagnosis and classification of diabetes mellitus and its complications. Part 1: Diagnosis and classification of diabetes mellitus provisional report of a WHO consultation. Diabetic Med 15:539

10. The Juvenile Diabetes Research Foundation International. About the GoKinD Study. Available from http://www.jdrf.org/index.cfm? fuseaction=home. viewPage\&page id=B9C33021-1321-C8340382E079E7865807, accessed 4 August 2008

11. Pantel J, Machinis K, Sobrier ML et al (2000) Species-specific alternative splice mimicry at the growth hormone receptor locus revealed by the lineage of retroelements during primate evolution. J Biol Chem 275:18664-18669 